\title{
Multiple Personality Disorder and False Memory Syndrome
}

\author{
HAROLD MERSKEY
}

Multiple personality disorder is a controversial diagnosis which has been examined critically and at length in this journal (Fahy, 1988; Merskey, 1992; Piper, 1994) and in two monographs (Kenny, 1986; Aldridge-Morris, 1989). A marked growth in the number of reported cases started in the 1970s and accelerated enormously after the diagnosis was formally recognised in DSM-III. Whereas some 200 cases appeared in the world prior to 1980 (Bliss, 1986), hundreds of cases have now been identified by various authors. Ross (1987) suggested that $4.4 \%$ of psychiatric in-patients in a general hospital unit had MPD. Soon afterwards Ross et al (1989) argued that MPD may afflict as many as $5 \%$ of college students in Canada, and presumably elsewhere.

The number of cases is not all that has grown. Increasing numbers of personalities have been described for each case (Merskey, 1992). Hilgard (1988) pointed out that the increasing numbers of such personalities were ". . . bound to raise doubts about diagnoses". At the same time, everyone interested in the field is aware that MPD is rarely diagnosed outside the US and Canada. Recently, Spiegel (1993) reported that the late Dr Cornelia Wilbur, the original therapist in the case of 'Sybil' (Schreiber, 1973), had encouraged the adoption of named personalities. He maintained that the diagnosis was artificial. Further support for those who regard the diagnosis as improbable and relate it to insufficient exercise of the critical faculty comes from the views of a recent president of the International Society for Dissociative Disorders, Dr Colin Ross (1993), who avers that the United States Central Intelligence Agency implanted MPD into children, so that some of the alter personalities "could carry more information" and that the same agency has inspired the current criticisms of MPD in order to discredit the diagnosis, so that reports of the discovery of these implanted 'alters' will not be believed. It seems that once the critical faculty is loosened even slightly, and the notion of one or two extra personalities is accepted, there is no end to the developments that may occur.

Fahy et al (1989) and Freeland (1993) reported cases which had been diagnosed as MPD, but were treated better without that diagnosis, and for which other diagnoses were preferred. Even in Canada, where the diagnosis has been almost as popular as in the US, Mai (1992) found that $68 \%$ of 175 psychiatrists (out of 268 circularised) had never made the diagnosis, $41 \%$ had not seen a case, and the figures for the occurrence of the disorder were best explained by a small number of psychiatrists making a large number of diagnoses. The World Health Organization (1992), in the 10th revision of the International Classification of Diseases, said of MPD that if it exists at all it should be categorised under F44.8, "Other Dissociative (Conversion) Disorders". In response to some of the earlier criticisms, the American Psychiatric Association (1994) made modest changes in DSM-IV. The DSM-IV criteria are as follows:

"A. The existence within the person of two or more distinct identities or personality states (each with its own relatively enduring pattern of perceiving, relating to and thinking about the environment and self).

B. At least two of these identities or personality states recurrently take control of the person's behaviour".

The new version of MPD is called 'dissociative identity disorder (formerly multiple personality disorder)' and the above criteria have two further qualifications: "Inability to recall important personal information that is too extensive to be explained by ordinary forgetfulness", and a statement that excludes states due to a substance-induced or general medical disorder. There is also another small change with larger implications. The criterion that at least two of these personalities or personality states recurrently take full control of the person's behaviour has been altered by the deletion of the word 'full'. Thus, according to the definition, it is possible for a personality to take partial control, or two or more personalities can share control. How this can happen while memory is lost may puzzle the thoughtful. The response of the American Psychiatric Association has come essentially from the same committee which wrote the DSM-III-R version and even the DSM-III version. Thus, for the next few years American psychiatry and some of Canadian psychiatry will preserve a diagnosis that is facing a radical challenge to its existence.

Part of the attention that MPD now receives is related to questions of sexual abuse. Hacking (1992) observed that since the case of 'Sybil', childhood sexual abuse has become tied to the origins of MPD. 
The proponents of MPD canvass potential patients for a history of sexual abuse in childhood and report it in the great majority of cases (Ross et al, 1990). This notion of MPD being linked to abuse, even in very early childhood, has been extended to a larger concept that there are many 'adult survivors of childhood sexual abuse' in need of treatment, with or without MPD, and therapists for MPD offer themselves as leading participants in the work of curing the effects of sexual abuse. The memories of this abuse can be taken from the earliest periods of life. Doris Bryant and Lynda Shirar, two 'licensed marriage, family and child counselors' in California, together with their patient Judy Kessler (Bryant et al, 1992), described the recollections of the patient from her crib onwards, according to which she was ritually sexually abused and used in pornographic films by an unspecified number of adults. While the account is not very specific for dates and ages, it clearly implies serious neglect from birth onwards and seems to suggest that long-continued sexual abuse started in infancy.

It is suggested that many survivors can recover memories which were repressed in childhood and are disinterred later by skilful psychotherapy in order to release the adult from the burdens of the past. This process has brought psychiatry into contact with a widespread and unexpected social phenomenon. In this case, adults, mostly in the third and fourth decades of life, have begun to accuse their fathers, and sometimes other relatives including their mothers, of sexual abuse in childhood, which was never revealed, and which indeed they themselves had forgotten until the 'memory' was restored to them.

Typically, the adult daughter of elderly parents enters psychotherapy for depression, problems in adjustment, anxiety, difficulties after a divorce, job problems or stress of mild to moderate severity. In the course of therapy she and the therapist determine that she was abused by her father during her childhood. The accusations against the previously blameless father are usually not supported by the mother and other siblings, who commonly reject the accusation. There is no other indication of childhood events which might point to an enormous single trauma, or recurring traumata. The family is not dysfunctional and has no resemblance to the many dysfunctional families with serious problems. In the hands of therapists who believe in immediately searching for repressed memories of childhood abuse, the patient is quickly encouraged to produce evidence of such events from childhood. If memories do not come quickly, more pressure is exerted. Once a memory is produced the patient is told to stay away from members of the family until they acknowledge their wickedness and guilt, and lawsuits may be commenced to pay for the damage done and for further therapy. Families are torn apart on uncorroborated evidence, based upon the solicited recall by individuals who have had no conscious knowledge of the matter in the $10,20,30$ or even $\mathbf{4 0}$ years since the events which are said to have taken place.

In 1992 the simultaneous recognition by psychiatrists in Philadelphia of several such cases led a number of professional advisers to support the start of the False Memory Syndrome Foundation, which was organised by the parents of a family in which the father was accused. This FMS Foundation offers membership to accused families and has a Scientific Advisory Board recruited independently. In the two years since its inception the FMS Foundation has received information on 11000 families, principally in the US and Canada, in which an alleged false accusation has been made, and it has acquired 8000 families as members. A survey conducted among families joining the Foundation is currently continuing. Data based on survey documents returned by $58 \%$ of the 487 families circularised in 1992 provide the basis for the general pattern described above (False Memory Survey Foundation, 1993). The picture which emerges is of families in which the accusing children, for the most part, had happy childhoods, never complained of abuse at the time, and often excelled in school. (To date it is a very middle-class group that has responded.) Interestingly, as many as $45 \%$ of those accused had no specific information on the nature of the accusation, and $18 \%$ reported that there were allegations of satanic ritual abuse. The Foundation is as much against sexual abuse as any other group of responsible citizens - if not more so. Nevertheless, it has become the subject of a bitter controversy with such remarks as "This is the perpetrators fighting back" (Herman, 1993), which assume guilt, ignore the large numbers within the Foundation who are not accused, and implicate the Scientific Advisory Board which was recruited for its independence of such allegations, as well as its professional standing.

The consequences of the accusations are farreaching. As a result of them, two-thirds of the parents reported having no contact with their accusing child, and $39 \%$ had lost contact with their grandchildren. Of 708 siblings, $86 \%$ do not accuse their parents, and $71 \%$ do not believe the accusations. The distress and bewilderment of the accused are impressive.

The same problem has been identified in Britain, and a British False Memory Society has been founded with a prominent Board of Trustees and a very distinguished academic board, including psychologists, and psychiatrists with interests in memory, dynamic personality, developmental psychology, and forensic psychiatry. 
There is little, if any, reason to believe in the validity of recovered memories, especially when a significant proportion are reported from the age of three years or less. Cognitive psychologists and experimental students of memory agree that the recall of memories is an active process (Loftus, 1993). Memories which are not refreshed or kept in mind repeatedly, or renewed as a result of rehearsal, or the occurrence of other events to reinforce them, will decay. They are not recoverable as the identical perceptions that were first experienced. Memory itself is thought to involve active reconstruction rather than the revelation of something that had merely dropped out of sight and remained unchanged. It is not to be thought of as a clear etching retained in a sealed room in the mind and totally accessible provided we can find the key to the room.

Allegations which rely upon repressed memories have led to a closer examination of the idea of repression. It transpires that the psychological literature is unable to provide scientific evidence that repression occurs as a mental mechanism - although it has been looked at very closely (Holmes, 1990). This brings the practising psychiatrist who wishes to believe in repression face to face with a considerable dilemma. It has been all right to treat patients on the basis of dynamic notions of repression so long as the concept was only one which was exchanged between therapist and patient and merely served to revise, in a positive fashion, the patient's view of himself or herself in the world. Using repression as an idea which works to the detriment of other people, disrupts families, wipes out the life savings of parents, abolishes their contact with children and grandchildren, and embroils some in painful legal battles, is another matter altogether and not compatible with the old principle "first do no harm". This forces psychiatry into re-thinking what is meant by repression, how much we can rely upon it, and how much we can observe or encourage a belief in the classical Freudian defence mechanisms. Clinical experience may be cited to the effect that repression does occur in the face of traumatic experiences with grave impact. If so, the time has come for a critical examination of that evidence which at present remains unsystematic and anecdotal. At the moment it appears to this writer that we should still retain the concept of repression for conditions of acute or chronic conflict, but that it is not tenable as an explanation for the sustained loss of memory, and it is probably no longer useful as a concept dealing with past experience.
References

Aldridoe-Morris, R. (1989) Multiple Personality. An Exercise in Deception. London: Lawrence Erlbaum.

American Psychiatric Associnton (1987) Diagnostic and Statistical Manual of Mental Disorders (3rd edn, revised) (DSM-III-R). Washington, DC: APA.

- (1994) Diagnostic and Statistical Manual of Mental Disorders (4th edn) (DSM-IV). Washington, DC: APA.

Buss, E. L. (1986) Multiple Personality, Allied Disorders and Hypothesis. New York: Oxford Medical Publications.

Bryant, D., Kessler, J. \& Shirar, L. (1992) The Family Inside Working with the Multiple. New York: Norton.

FAHY, T. A. (1988) The diagnosis of multiple personality disorder. A critical review. British Journal of Psychiatry, 153, 597-606. -, ABas, M. \& Brown, J. C. (1989) Multiple personality. A symptom of psychiatric disorder. British Journal of Psychiatry, 154, 99-101.

False Memory Syndrome Foundation (1993) Family Survey Results. Philadelphia: FMSF.

Freeland, A., Manchanda, R., Chiu, S., et al (1993) Four cases of supposed multiple personality disorder: Evidence of unjustified diagnoses. Canadian Journal of Psychiatry, 38, 245-247.

HACKING, I. (1992) Multiple personality disorder and its hosts. History of Human Science, 5, 3-31.

Herman, J. L. (1993) Proceedings of the 146th Annual Meeting of the American Psychiatric Association. Adult Memories of Childhood Trauma: Current Controversies. Contribution to Discussion. May 26, 1993.

Hiloard, E. R. (1988) Professional scepticism about multiple personality. Journal of Nervous and Mental Disease, 176, 532.

HoLmes, D. S. (1990) The evidence for repression: An examination of 60 years of research. In Repression and Dissociation. Implications for Personality, Theory, Psychopathology and Health (ed. J. L. Singer), pp. 85-102. Chicago: University of Chicago Press.

KeNNY, M. G. (1986) The Passion of Ansel Bourne. Washington, DC: Smithsonian Institute.

LofTus, E. F. (1993) The reality of repressed memories. American Psychologist, 48, 518-537.

MAI, F. (1992) Multiple personality disorder: a debate. Presented at Annual Meeting of Canadian Psychiatric Association, Montreal.

MersKey, H. (1992) The manufacture of personalities. The production of multiple personality disorder. British Journal of Psychiatry, 160, 327-340.

PIPer, A. JR. (1994) Multiple personality disorder: A critical review. British Journal of Psychiatry, 164, 600-612.

Ross, C. A. (1987) Inpatient treatment of multiple personality disorder. Canadian Journal of Psychiatry, 32, 779-781.

(1993) Comments. In Mistaken Identities. Canadian Broadcasting Corporation. The Sth Estate, 9 November 1993. Ottawa: Media Tapes and Transcripts.

-, Miller, S. D., Renger, P., et al (1990) Structured interview data on 102 cases of multiple disorder from four centers. American Journal of Psychiatry, 147, 596-601.

, Norton, G. R. \& FrAser, G. A. (1989) Evidence against the iatrogenesis of multiple personality disorder. Dissociation, 2, 61-65.

Schreiber, F. R. (1973) Sybil. Chicago: Henry Regnery.

SPIEOrL, H. (1993) Comments. In Mistaken Identities. Canadian Broadcasting Corporation. The Sth Estate, 9 November 1993. Ottawa: Media Tapes and Transcripts.

World Hralth Oroanization (1992) International Classification of Diseases (10th edn). Geneva: WHO.

Harold Merskey, Professor of Psychiatry, University of Western Ontario, London, Ontario, Canada

(First received 23 May 1994, final version 14 September 1994, accepted 7 October 1994) 